\title{
CORRECTION
}

\section{Correction to: Use of combined cardiac and lung ultrasound to predict weaning failure in elderly, high-risk cardiac patients: a pilot study}

Belaid Bouhemad ${ }^{1,2^{*}} \mathbb{D}$, Francesco Mojoli ${ }^{3}$, Nicolas Nowobilski ${ }^{1}$, Arif Hussain ${ }^{4}$, Isabelle Rouquette ${ }^{5}$, Pierre- Grégoire Guinot ${ }^{1}$ and Silvia Mongodi ${ }^{3}$

@ 2020 Springer-Verlag GmbH Germany, part of Springer Nature

\section{Correction to: Intensive Care Med \\ https://doi.org/10.1007/s00134-019-05902-9}

The original version of this article unfortunately contained a mistake. Two of the authors forgot to mention recent collaborations in their COI. The correct COI would have been: Dr Silvia Mongodi received feed for lectures from General Electrics; and Professor Francesco Mojoli received feed for lectures from General Electrics, Hamilton Medical and SEDA SpA. The Authors apologise for the missing information.

\section{Author details}

${ }^{1}$ Department of Anaesthesiology and Intensive Care, C.H.U. Dijon, BP 77908 ,

21709 Dijon Cedex, France. ${ }^{2}$ Université Bourgogne Franche-Comté, LNC UMR866, 21000 Dijon, France. ${ }^{3}$ Department of Anaesthesia and Intensive Care, Istituto Di Ricovero E Cura a Carattere Scientifico, Policlinico San Matteo Foundation, Pavia, Italy. ${ }^{4}$ Department of Anaesthesia and Intensive Care, King Abdulaziz Medical City, National Guard Health Affairs, Riyadh, Saudi Arabia.

${ }^{5}$ Department of Anaesthesia, CH Princesse Grace, Monte Carlo, Monaco.

\section{Publisher's Note}

Springer Nature remains neutral with regard to jurisdictional claims in published maps and institutional affiliations.

Published online: 10 February 2020

\footnotetext{
*Correspondence: belaid_bouhemad@hotmail.com

1 Department of Anaesthesiology and Intensive Care, C.H.U. Dijon, BP

77908, 21709 Dijon Cedex, France

Full author information is available at the end of the article
}

\section{空 Springer}

